\title{
Neuro-fuzzy-based smart DSS for crop specific irrigation control and SMS notification generation for precision agriculture
}

\author{
Ambarish G. Mohapatra* \\ Department of Applied Electronics and Instrumentation, \\ Silicon Institute of Technology, \\ Bhubaneswar, 751024, Odisha, India \\ Email: ambarish.mohapatra@gmail.com \\ *Corresponding author
}

\section{Saroj Kumar Lenka}

Department of Information Technology, Mody University, Lakshmangarh, 332311, Rajasthan, India Email: lenka.sarojkumar@gmail.com

\begin{abstract}
A feed forward neural network and fuzzy logic-based hybrid smart decision support system (DSS) for crop specific irrigation notification and control in precision agriculture (PA) is proposed in this paper. This proposed neuro-fuzzy smart DSS can be implemented in any farm land, green-house and poly-house for efficient irrigation management and control for PA. A feed forward neural network is trained and linear regression is performed to predict soil moisture content (MC) in hourly basis. The predicted soil MC is utilised by fuzzy logic-based smart DSS model to produce SMS notification to the farmer. The proposed DSS model can work on real-time mode using National Instruments LabVIEW. This hybrid smart DSS prediction algorithm is implemented using data group of 24 cases measured in the farming land located in Bhubaneswar, the southern part of India. Crop wise evapotranspiration is also calculated using Blaney-Criddle method to notify the farmers via SMS service.
\end{abstract}

Keywords: feedforward neural network; linear regression; LabVIEW; decision support system; DSS; fuzzy logic; SMS notification; GSM modem interface.

Reference to this paper should be made as follows: Mohapatra, A.G. and Lenka, S.K. (2016) 'Neuro-fuzzy-based smart DSS for crop specific irrigation control and SMS notification generation for precision agriculture', Int. J. Convergence Computing, Vol. 2, No. 1, pp.3-22.

Biographical notes: Ambarish G. Mohapatra completed his Master course in 2008 from VIT University, India and has occupied a Senior Lecturer position at the Department of Applied Electronics and Instrumentation Engineering in Krupajal Engineering College, India from 2008 to 2010. Currently, he is working as an Assistant Professor in Silicon Institute of Technology, India and he is continuing his research in the area of internet of things (IoT) and high performance wireless sensor network (WSN) for precision agriculture environment. He is having number of national and international conference as well as journal papers in the field of engineering and technology. His research 
interests are micro-electro mechanical systems (MEMS), wireless sensor network, intelligent instrumentation and virtual instrumentation. He lectures instrumentation devices and systems, electrical and electronic measurement, industrial process control dynamics at the Silicon Institute of Technology, India.

Saroj Kumar Lenka completed his PhD in Computer Science from Berhampur University, Berhampur. Currently, he is working as a Professor and Head of the Department of Computer Science and Engineering in Mody University of Science and Technology, Lakshmangarh, Rajasthan, India. He has a number of national and international conference as well as journal papers in the field of engineering and technology. His research interests are data mining, wireless sensor network, and cloud computing. He lectures cloud computing, data mining technology, distributed computing and BigData at Mody University of Science and Technology, Lakshmangarh - Rajasthan, India.

This paper is a revised and expanded version of a paper entitled 'Hybrid decision model for weather dependent farm irrigation using resilient backpropagation based neural network pattern classification and fuzzy logic' presented at the Proceedings of First International Conference on Information and Communication Technology for Intelligent Systems, Ahmedabad, 28-29 November 2015.

\section{Introduction}

Agriculture irrigation is truly an important practice in most cropping systems in semiarid and arid areas, and useful water applications and management are essential considerations. Self-propelled centre pivot in addition to linear-move irrigation systems usually apply water quite consistently; however, significant variations in soil properties and water availability exist across most fields (Crow and Wood, 2003). In these cases, the method for applying site-specific irrigation management to improve spatial and temporal variable conditions can enhance application efficiencies, minimise environmental impacts, as well as increase crop yields (Aggelopoulou et al., 2010, 2011). The application of a distributed in-field sensor network-based site-specific irrigation system having a smart decision support system (DSS) mechanism provides the feasible approaches to increase yield and quality while preserving water uses (Fountas et al., 2011). A great many other reports have investigated the possibility of the employment of feedback from wireless in-field sensing systems to control variable-rate irrigation systems, but few have fully integrated scalping systems (Fountas et al., 2004). The goal of the effort is to report the style, construction, and testing while using smart DSS-based irrigation mechanism that is easily integrated with WSN environment for in-field sensing and control within the variable rate irrigation system. Our aim is to develop a feed forward neural net with linear regression-based data prediction model for soil moisture content (MC) so that this can provide the prediction results in hourly basis by considering soil and environmental data (Gutiérrez et al., 2008). In addition to that a fuzzy 
logic-based SMS notification method used to notify the SMS to the farmer's handset is also integrated with the smart DSS to provide predicted soil MC. Real-time SMS are also transferred to the registered users using GSM modem interface with National Instruments LabVIEW.

Marco Nocita et al. (2013) computed the normalised soil moisture index (NSMI) to estimate the soil MC of the samples $\left(R^{2}=0.74\right)$, and used it to spectrally classify the samples according to their MC. M.E. Holzman et al. (2014) uses temperature vegetation dryness index (TVDI) and concluded a strong correlation with soil moisture measurements, with $\mathrm{R}^{2}$ values ranged from 0.61 to 0.83 and in addition it was in agreement with spatial pattern of soil moisture. Maciej Miernecki et al. (2014) compared several approaches to retrieve soil moisture (SM) using 1-band microwave radiometry. The approaches based on statistical regressions provided similar results and the best accuracy was obtained with the 'Saleh' methods based on either bi-angular or bipolarisation observations $\left(\mathrm{R}^{2} \approx 0.93, \mathrm{RMSE} \approx 0.035 \mathrm{~m}^{3} / \mathrm{m}^{3}\right)$. The LPRM and DCA algorithms were found to be slightly less successful in retrieving the 'reference' SM time series $\left(\mathrm{R}^{2} \approx 0.75, \mathrm{RMSE} \approx 0.055 \mathrm{~m}^{3} / \mathrm{m}^{3}\right.$ ) (Miernecki et al., 2014). In the similar context, Zhe Yin et al. (2013) uses NIR LED, photo-detectors and measured soil moistures which matches well with the predicted, with an $\mathrm{R}^{2}$ value above 0.7 .

The performance of the smart DSS model was successfully studied with $R^{2}$ (R-squared), root mean square error (RMSE), ratio of performance to deviation (RPD) and mean square error (MSE). The necessary evapotranspiration is additionally measured using Blaney-Criddle method. If no measured data on pan evaporation can be purchased locally, a theoretical method (e.g., the Blaney-Criddle method) to calculate the reference crop evapotranspiration (ETo) has to be used. Blaney-Criddle method dependant on parameters like daily maximum environmental temperature, daily minimum environmental temperature, mean daily percentage, latitude, mean reference crop evapotranspiration ETo in $\mathrm{mm} / \mathrm{day}$, crop factor $(\mathrm{kc})$ and required crop evapotranspiration (ET) in $\mathrm{mm}$ /day as shown in equation (2) and equation (3). These parameters are integrated within the DSS model to calculate crop wise required evapotranspiration. This model is attached to the DSS system for generating crop wise notifications for the farmers. A fuzzy logic-based SMS notification system is also integrated while using the predicted soil MC for evaluating adequate SMS plan to the farmer's handset. Real-time SMS will also be transferred to the users using GSM modem interface with National Instruments LabVIEW. The complete system could be done using MATLAB but we have chosen LabVIEW because it is fast and simple construction of the graphical user interface that facilitates the updating of parameters (no need to interfere with the code) and elegant presentation of the results. Creating a comparable user interface in MATLAB could be more painful and limited. Another advantage of LabVIEW is that most MATLAB functions are accessible from LabVIEW via the MathScript Node, which can actually pass data to $\mathrm{m}$ code, execute it and get results back. The proposed neuro-fuzzy-based DSS model in precision agriculture (PA) is discussed in Section 2 of this paper. The complete DSS process flow is also explained in Section 3. The performance analysis of this smart DSS model is discussed in the Section 4 of this article. At last the design of smart DSS model has been concluded. 


\section{Proposed neuro-fuzzy-based smart DSS in PA}

This work emphasises on better prediction of soil MC in each hourly basis. The predicted MC is taken as input to the DSS model for irrigation control and suitable SMS notification generation for the farmers using fuzzy logic. The fuzzy logic systems are based on 'degrees of truth' rather than true or false model (Papageorgiou et al., 2011). A graphical user interface (GUI) using National Instruments LabVIEW is also developed to visualise the data prediction results as well as error statistics. As soil MC depends on many environmental parameters (environmental temperature, environmental humidity, environmental $\mathrm{CO}_{2}$ level, sunlight intensity, sunrise time, air flow rate), soil parameters (soil temperature, soil type current soil MC) (Mohapatra and Lenka, 2015). The proposed smart DSS will collect soil and environmental data from WSN environment to predict soil MC in each hourly basis by considering current time stamp. Soil moisture evaporation rate depends on the above parameters. These parameters are sensed by means of corresponding wireless sensors and the real-time data is taken input to the prediction model. The complete block diagram is described in Section 2.1.

\subsection{Process flow diagram of smart DSS in PA}

The proposed agriculture DSS model contains a WSN-based real-time data collection scheme. In this work, we have used Libelium Waspmote Agriculture Sensor Board consisting of air temperature sensor, air humidity sensor, soil temperature sensor, soil moisture sensor, solar radiation sensor. The WSN nodes are configured as mesh network configuration and the real-time data is collected in a server node. The server node is designed using Raspberry PI board containing Zigbee as well as wifi connectivity. The WSN node and server communication is established using Zigbee and the remote DSS server communication with WSN server node is established using wifi connectivity (Mohapatra and Lenka, 2016). The WSN-based real-time agriculture data collection architecture is shown in Figure 1(a). The complete soil MC prediction model and DSS scheme for irrigation control is shown in Figure 1(b). All sensor data were collected and arranged in proper structure for soil MC prediction. The aggregated real-time agriculture data is taken as input to the feedforward neural network training and linear regression model. The predicted soil MC data is taken as input to the DSS model for generation of suitable SMS notification on the mobile phone handset of farmer. The suitable SMS notifications are generated using fuzzy logic model. Five inputs like soil MC difference as mentioned in equation (1), environmental temperature (degree centigrade), environmental humidity (\%), wind speed (knots) and sun light intensity (Lux) are used to control the irrigation valve positions, and generation of suitable notifications (Mohapatra and Lenka, 2016). The fuzzy model is designed with 52 different fuzzy rules for generating six types of SMS notifications and three different valve positions. The fuzzy model is configured as Mamdani type with five inputs of triangular shaped membership functions. The complete visualisation is also done using LabVIEW GUI. 
Figure 1 (a) Block diagram of WSN-based real-time data collection scheme (b) Block diagram of soil MC prediction model along with DSS for irrigation (see online version for colours)

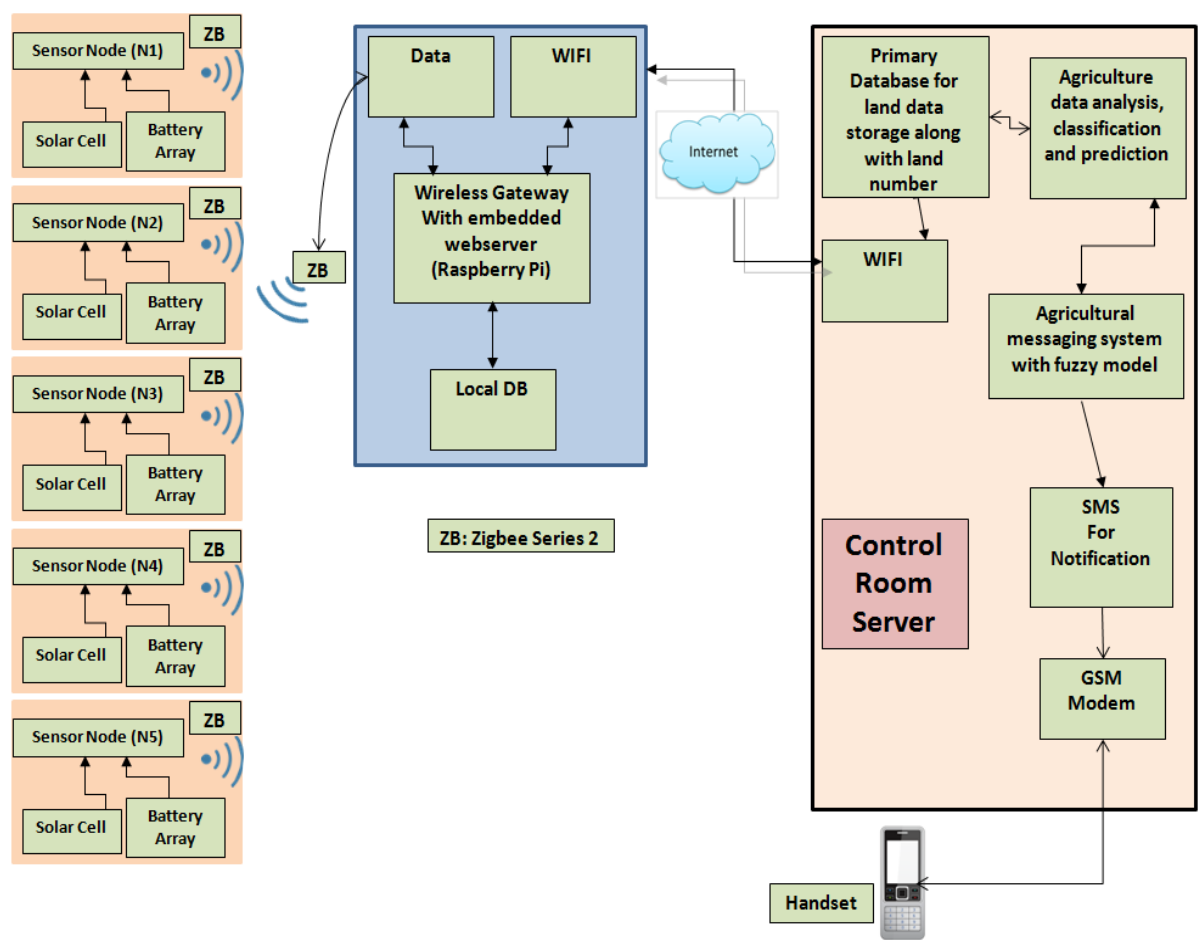

(a)

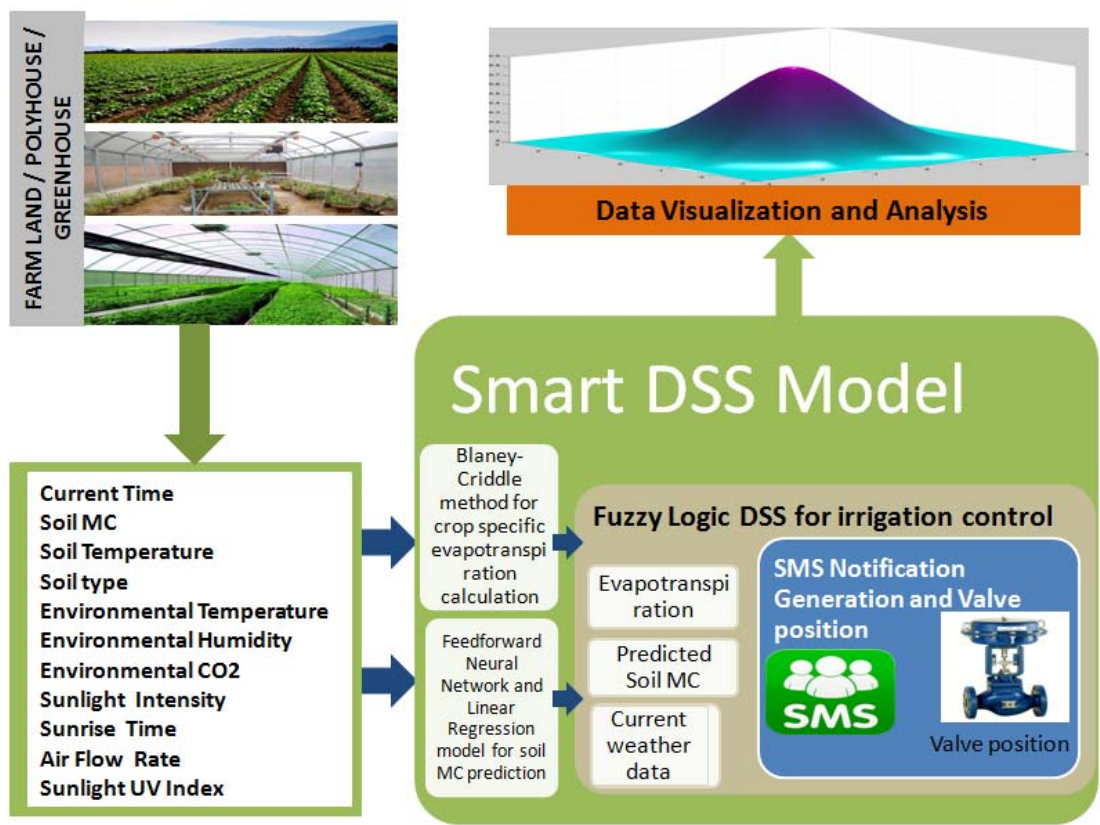

(b) 
Figure 2 Feed forward network configuration for soil MC prediction model (see online version for colours)

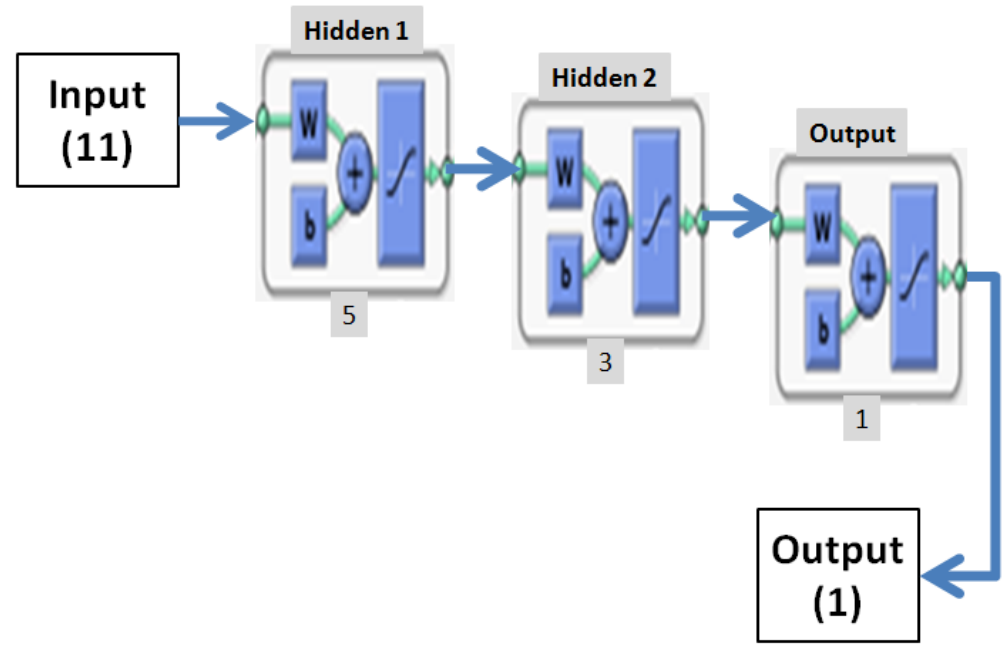

Figure 3 Feed forward network performance (see online version for colours)

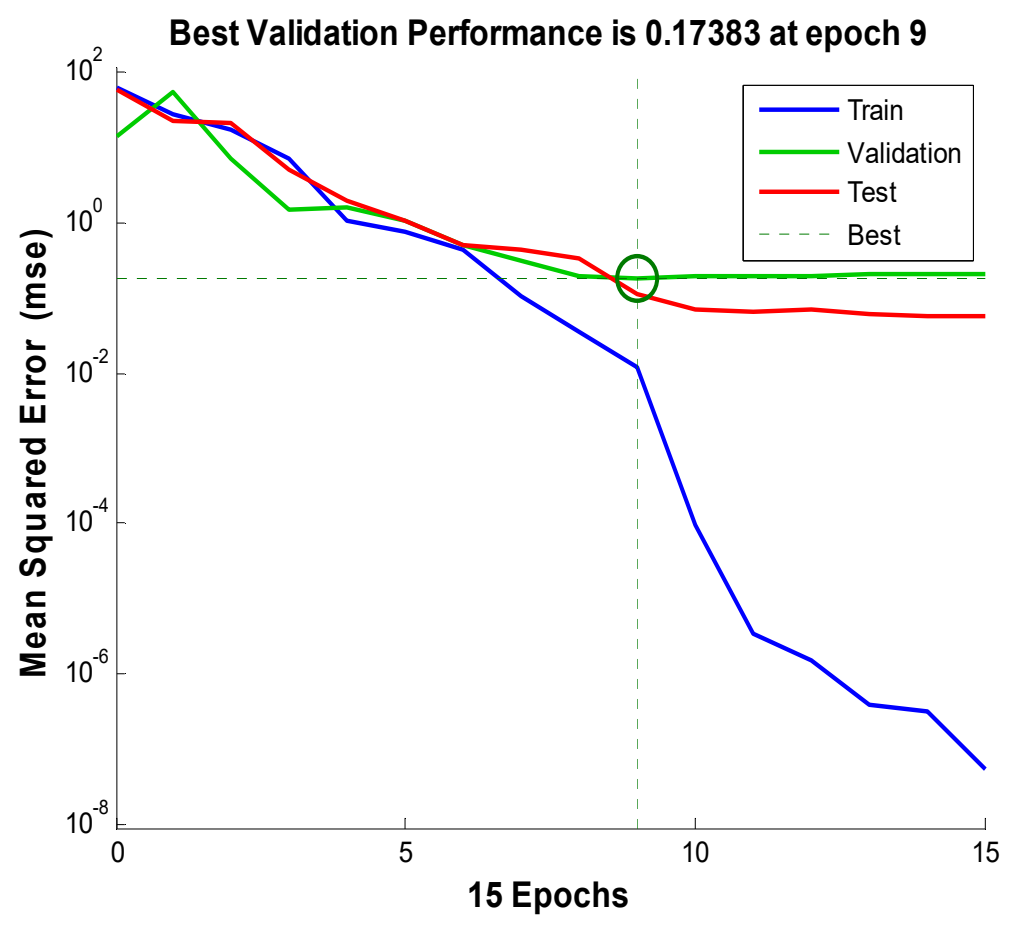


Figure 4 Feed forward network training state (see online version for colours)
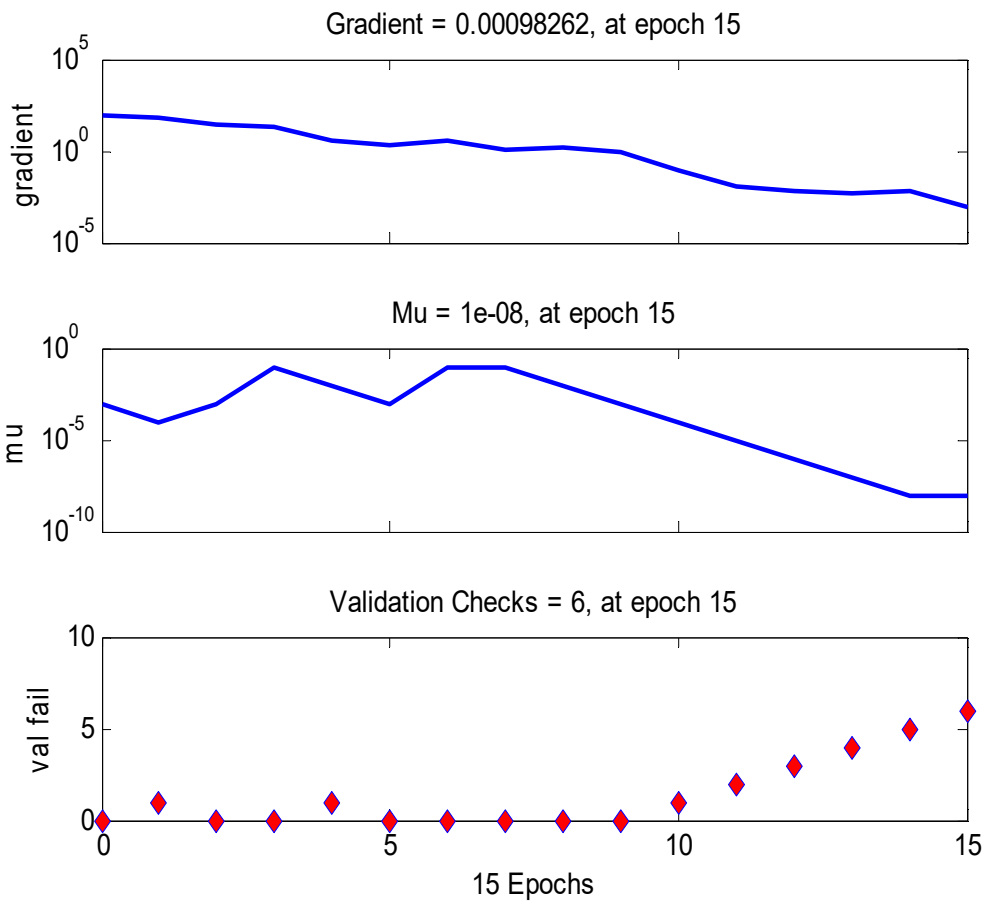

\subsection{Feed forward neural network training and linear regression model}

Feedforward networks include a volume of layers. The primary layer carries a connection from your network input. Each subsequent layer incorporates a connection in the last layer as well as the final layer generates the network's output. Feedforward networks can easily be utilised for those sorts of input to output mapping (Effendi et al., 2010). Hence a feedforward network which has a single hidden layer together with enough neurons within the hidden layers can certainly fit any finite input-output mapping problem (Fortin et al., 2010). The feedforward network is trained with five hidden layer inside first stage and three hidden layers from the second stage. The neural net configuration is shown in Figure 2. The feed forward neural network is trained and linear regression model is given to predict soil MC using suitable sensor dataset. The neural net is trained with $\mu$ value as $1.00 \mathrm{e}-08$. The neural network is tuned according to least MSE, RMSE and better RPD value. The RMSE, MSE and RPD obtained during training are mentioned in Table 3. The neural net performance and network training state is shown in Figure 3 and Figure 4 respectively. It is observed from the graph shown in Figure 3 that the network convergence is obtained after 15 numbers of epochs. 


\section{Flow chart of smart decision support system in PA}

The step wise implementation of smart DSS model for irrigation control in agriculture area is shown in Figure 5. This DSS model can be used as a generic model for irrigation control and suitable SMS notification generation for the farmer's handset.

Figure 5 Flow chart of soil MC prediction and SMS notification generation in smart DSS

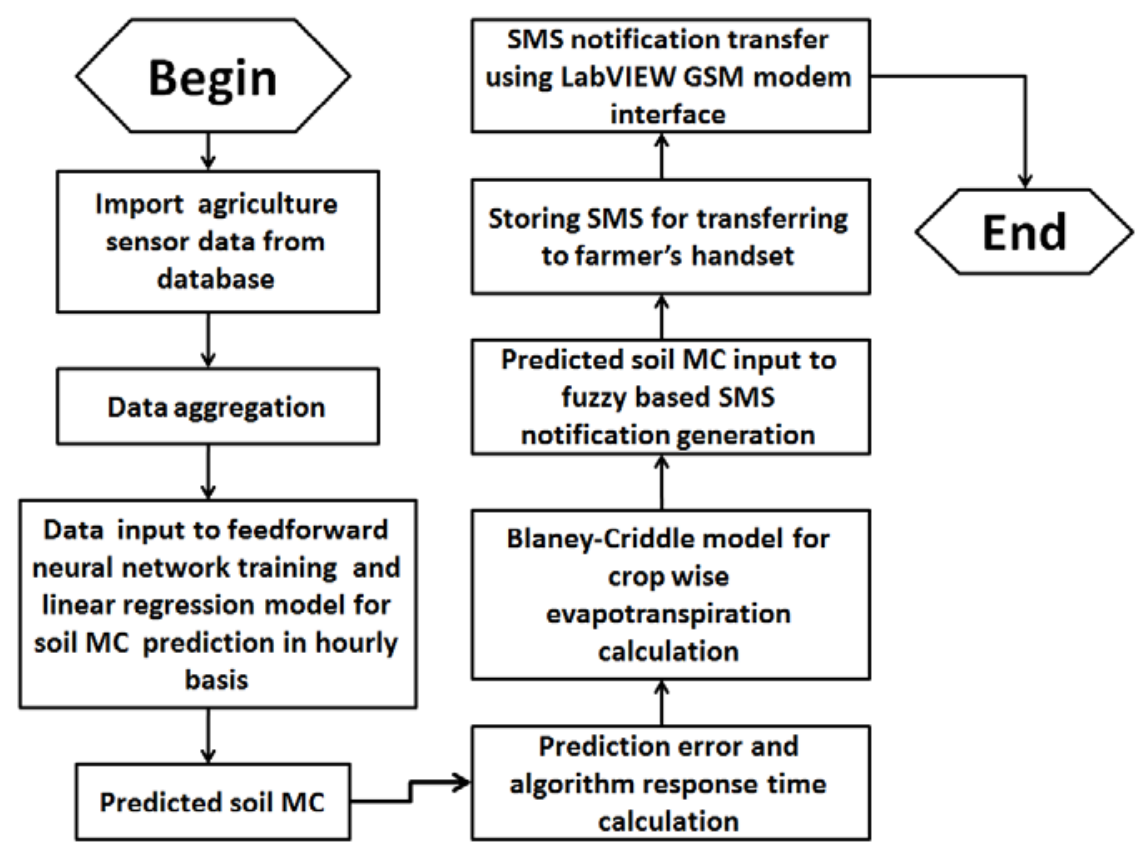

\section{Performance analysis of smart DSS model}

The soil MC prediction is done by considering several sensor inputs regarding soil data, environmental data. The feedforward neural network is trained and linear regression is performed to predict the soil MC after each hour. The soil MC variation for 24 hours is plotted with respect to time as shown in Figure 6(a). It is observed from Figure 6(a) that the soil MC decreases rapidly during $900 \mathrm{Hrs}$ to $1500 \mathrm{Hrs}$. Figure 6(b) shows the plot between soil MC output target and soil MC output predicted using neural network-based regression models. It is observed from the Figure 6(b) that the predicted soil MC matches the target soil moisture readings. The net irrigation from 01-Feb-2015 to 12-May-2015 and irrigation status for $02-\mathrm{Feb}-2015$ is shown in Figure 6(c). The error between these two as specified in equation (4) is also calculated along with the response time of the prediction algorithm. 
Figure 6 (a) Soil MC variation for 24 hours, (b) Soil MC Output target vs. soil MC output predicted using feedforward neural network model, (c) Net irrigation from 01-Feb-2015 to 12-May-2015 and irrigation status for 02-Feb-2015 (see online version for colours)

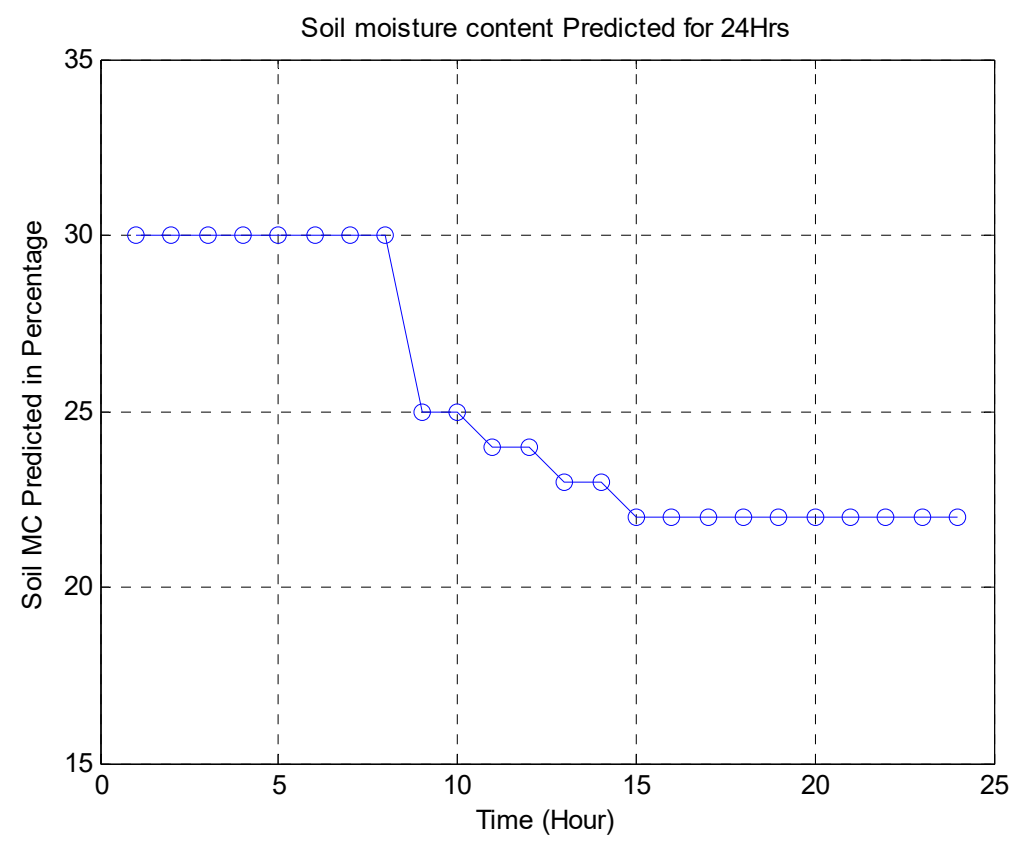

(a)

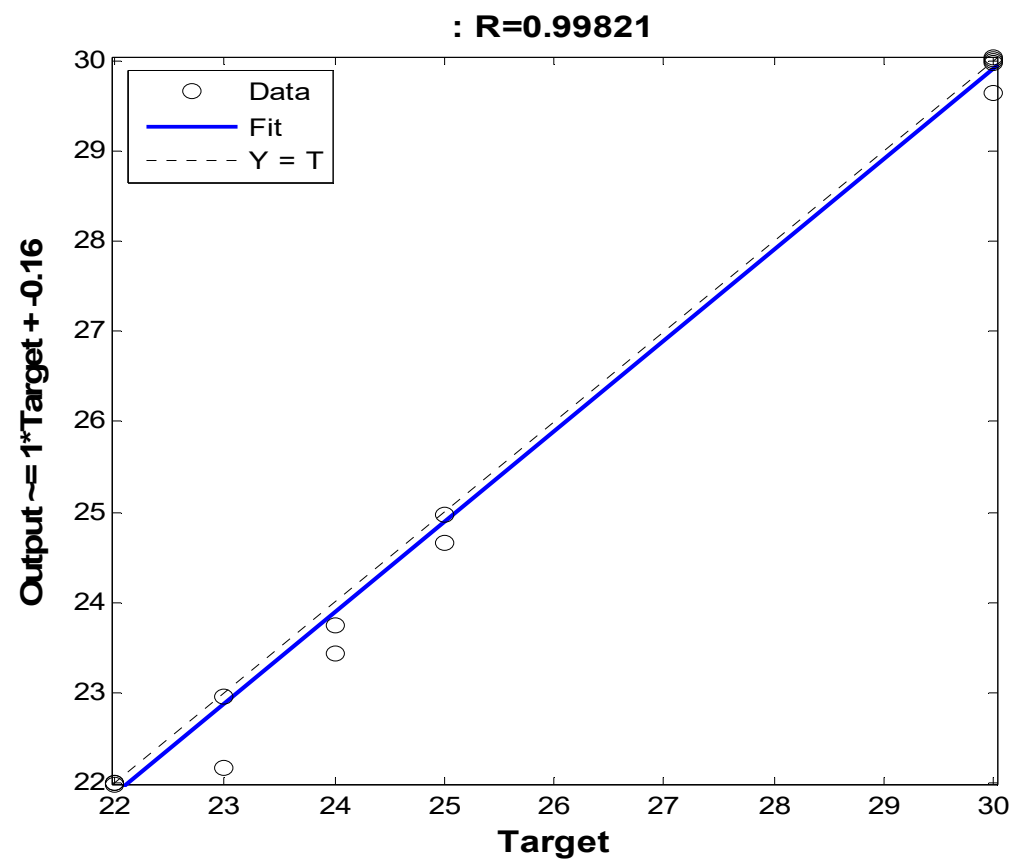

(b) 
Figure 6 (a) Soil MC variation for 24 hours, (b) Soil MC Output target vs. soil MC output predicted using feedforward neural network model, (c) Net irrigation from 01-Feb-2015 to 12-May-2015 and irrigation status for 02-Feb-2015 (continued) (see online version for colours)

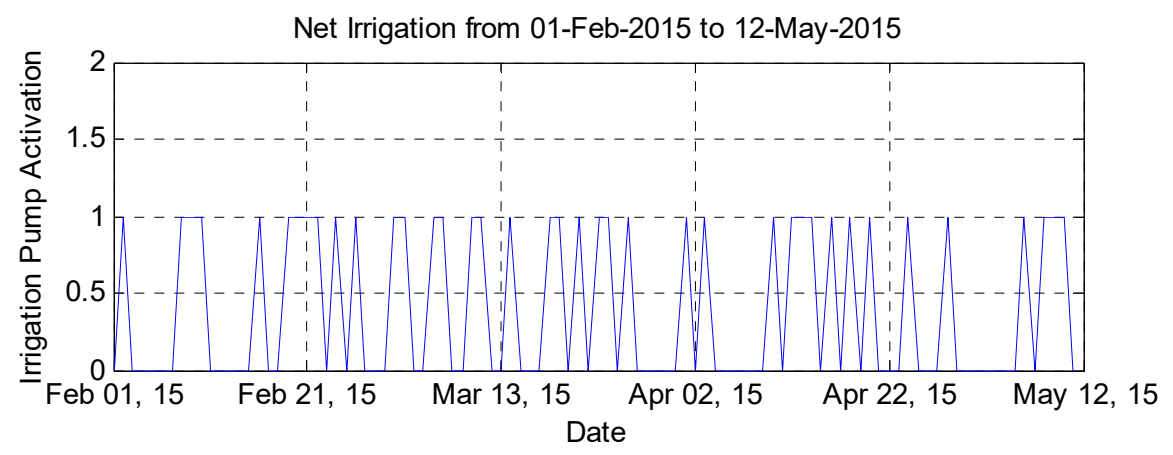

Net Irrigation on 02-Feb-2015

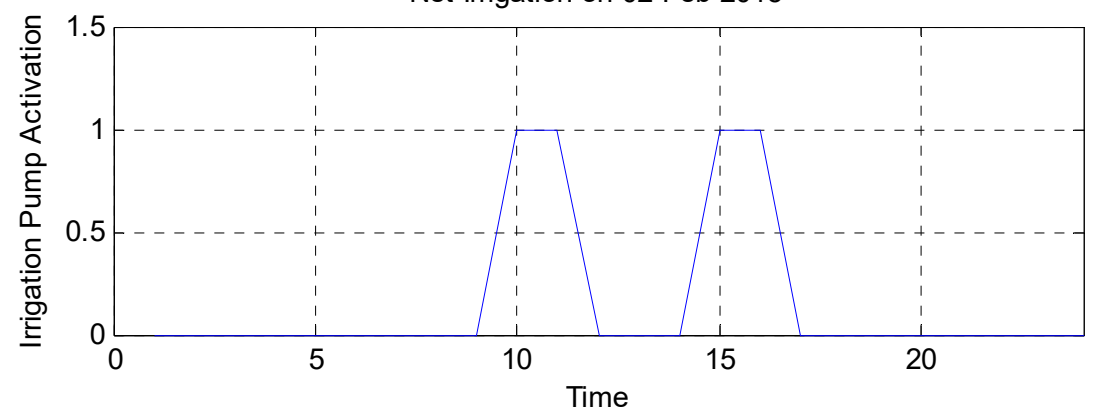

(c)

The Blaney-Criddle method of evapotranspiration approximation is performed by measuring mean daily temperature from daily maximum temperature and daily minimum temperature. The mean daily temperature is shown in equation (3). The reference evapotranspiration depends on the mean daily percentage of annual daytime hours and mean daily temperature. The crop wise crop factor $K_{c}$ is calculated from the reference table specified by FAO (Mohapatra and Lenka, 2016).

Soil MC difference $=$ Required Soil MC - Predicted Soil MC

$$
\begin{aligned}
& E T_{0}=\rho\left(0.46 T_{\text {mean }}+8\right) \\
& \mathrm{T}_{\text {mean }}=\frac{\mathrm{T}_{\text {max }}+\mathrm{T}_{\text {mean }}}{2}
\end{aligned}
$$

$E T_{0}$ reference crop evapotranspiration ( $\mathrm{mm} /$ day) as an average for a period of one month

$T_{\text {mean }} \quad$ mean daily temperature $\left({ }^{\circ} \mathrm{C}\right)$

$\rho \quad$ mean daily percentage of annual daytime hours. 
Figure 7 Membership functions of the inputs and outputs of fuzzy inference system as well as surface plot between different inputs and outputs, (a) triangular membership function for soil MC difference (b) triangular membership function for environmental temperature (c) triangular membership function for environmental humidity (d) triangular membership function for wind speed (e) triangular membership function for valve position (f) triangular membership function for SMS type (g) surface plot of wind speed, sunlight intensity vs. valve position (h) surface plot of wind speed, environmental humidity vs. sms_index (see online version for colours)

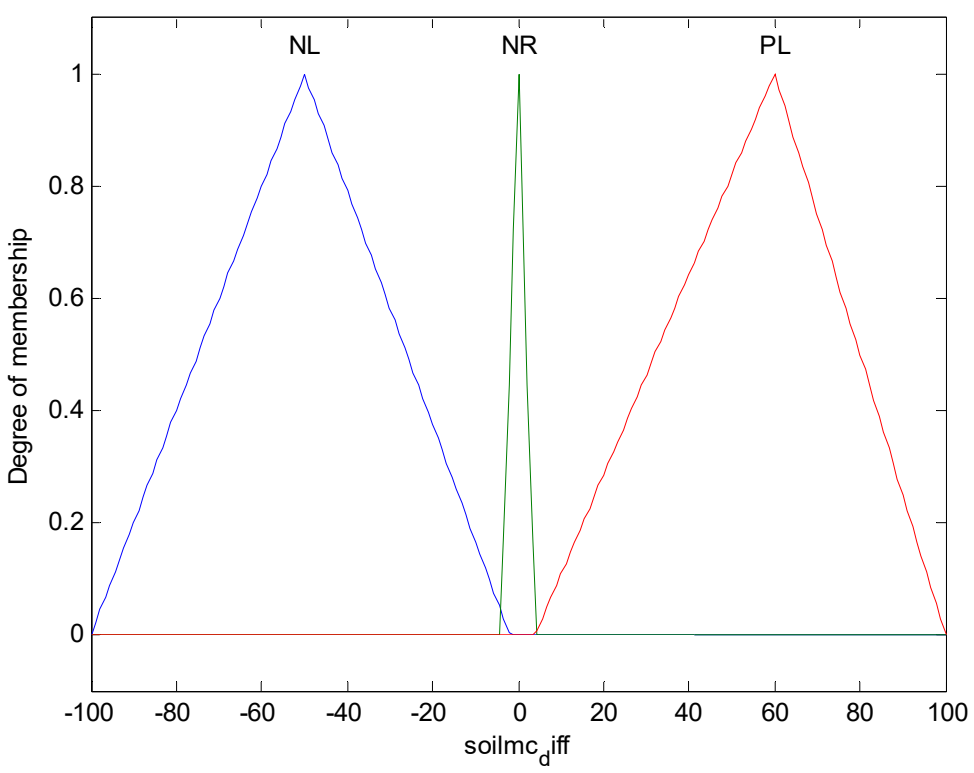

(a)

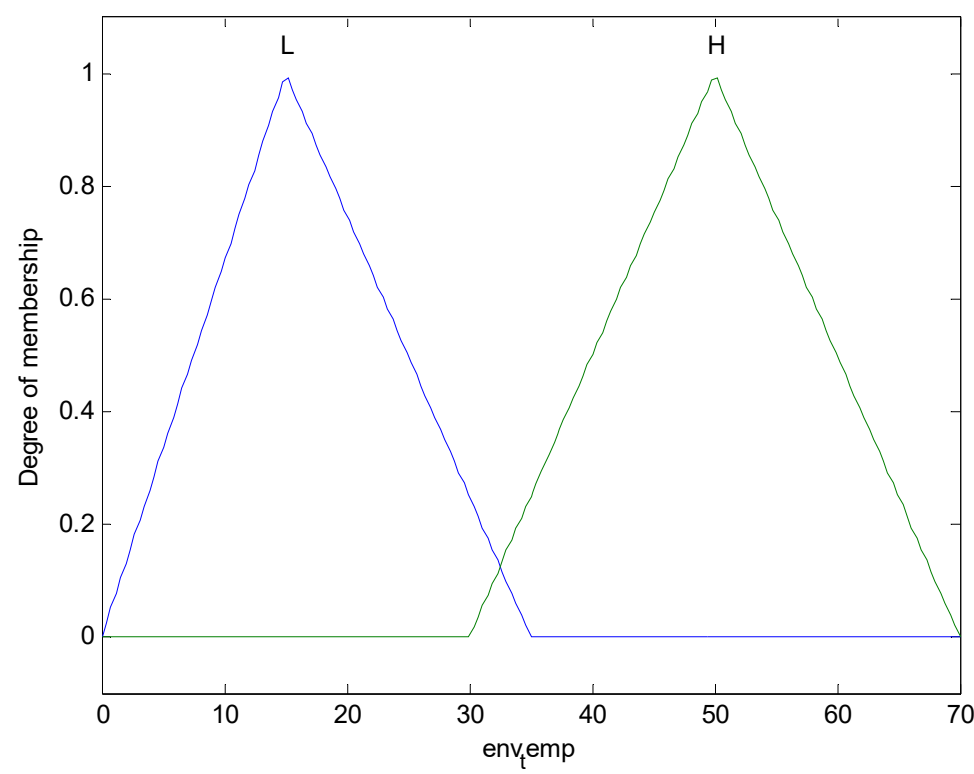

(b) 
Figure 7 Membership functions of the inputs and outputs of fuzzy inference system as well as surface plot between different inputs and outputs, (a) triangular membership function for soil MC difference (b) triangular membership function for environmental temperature (c) triangular membership function for environmental humidity (d) triangular membership function for wind speed (e) triangular membership function for valve position (f) triangular membership function for SMS type (g) surface plot of wind speed, sunlight intensity vs. valve position (h) surface plot of wind speed, environmental humidity vs. sms_index (continued) (see online version for colours)

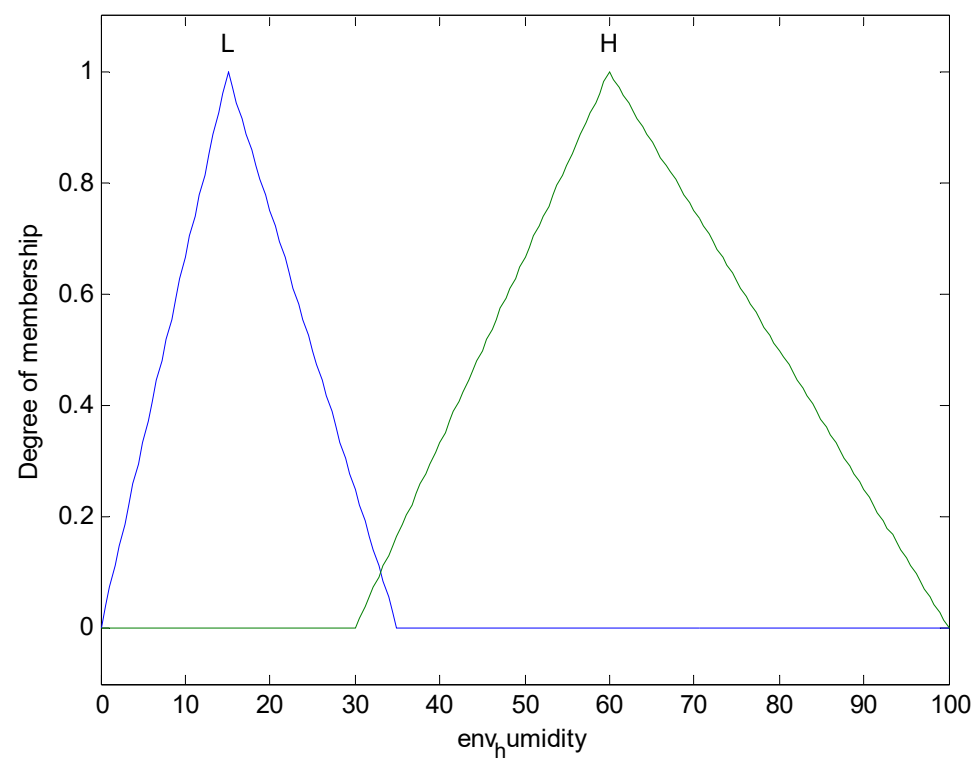

(c)

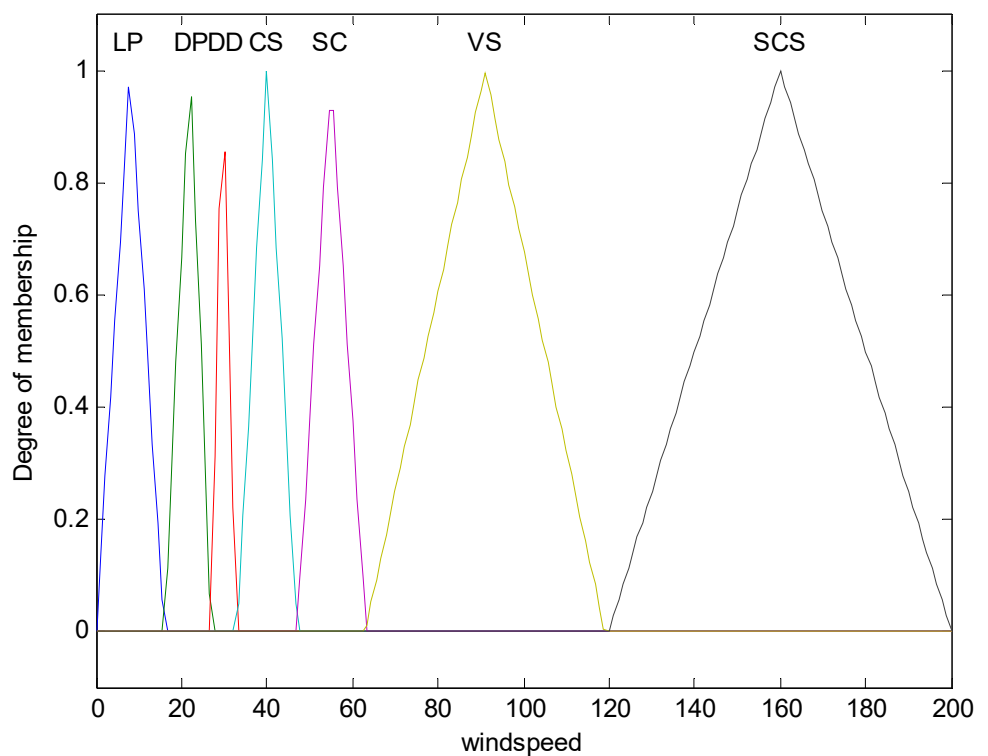

(d) 
Figure 7 Membership functions of the inputs and outputs of fuzzy inference system as well as surface plot between different inputs and outputs, (a) triangular membership function for soil MC difference (b) triangular membership function for environmental temperature (c) triangular membership function for environmental humidity (d) triangular membership function for wind speed (e) triangular membership function for valve position (f) triangular membership function for SMS type (g) surface plot of wind speed, sunlight intensity vs. valve position (h) surface plot of wind speed, environmental humidity vs. sms_index (continued) (see online version for colours)

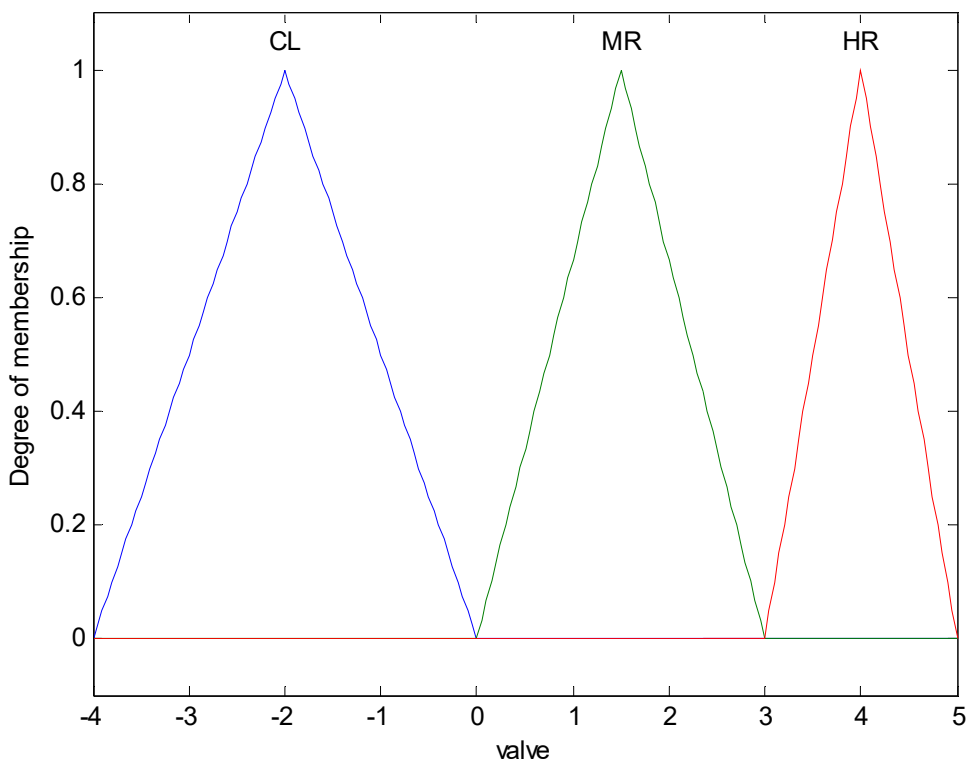

(e)

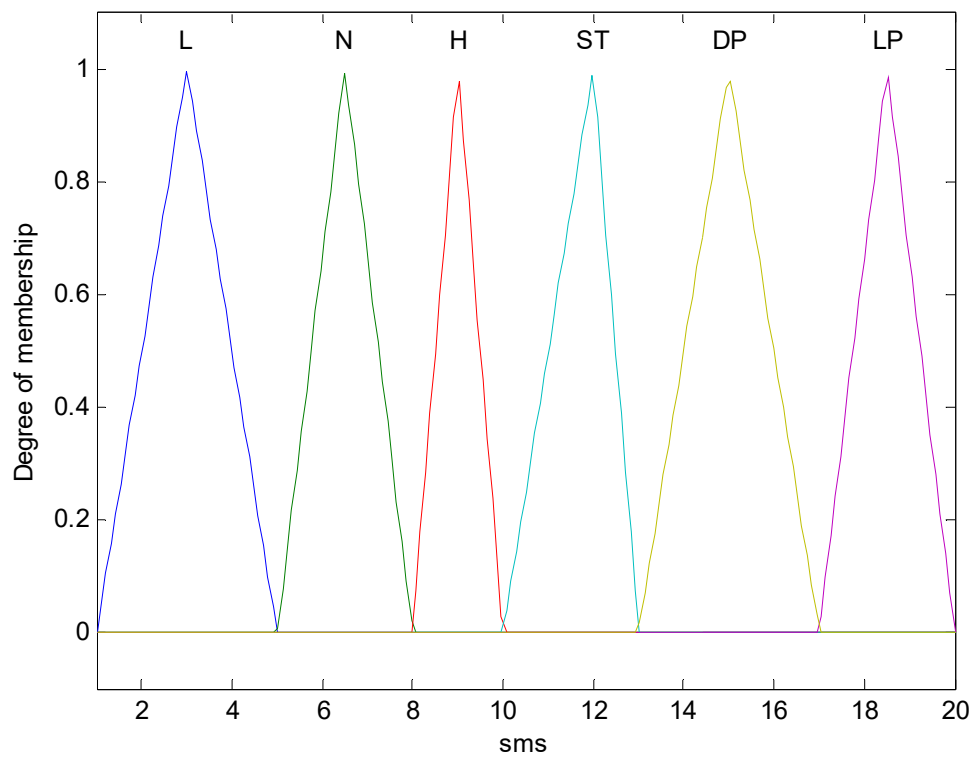

(f) 
Figure 7 Membership functions of the inputs and outputs of fuzzy inference system as well as surface plot between different inputs and outputs, (a) triangular membership function for soil MC difference (b) triangular membership function for environmental temperature (c) triangular membership function for environmental humidity (d) triangular membership function for wind speed (e) triangular membership function for valve position (f) triangular membership function for SMS type (g) surface plot of wind speed, sunlight intensity vs. valve position (h) surface plot of wind speed, environmental humidity vs. sms_index (continued) (see online version for colours)

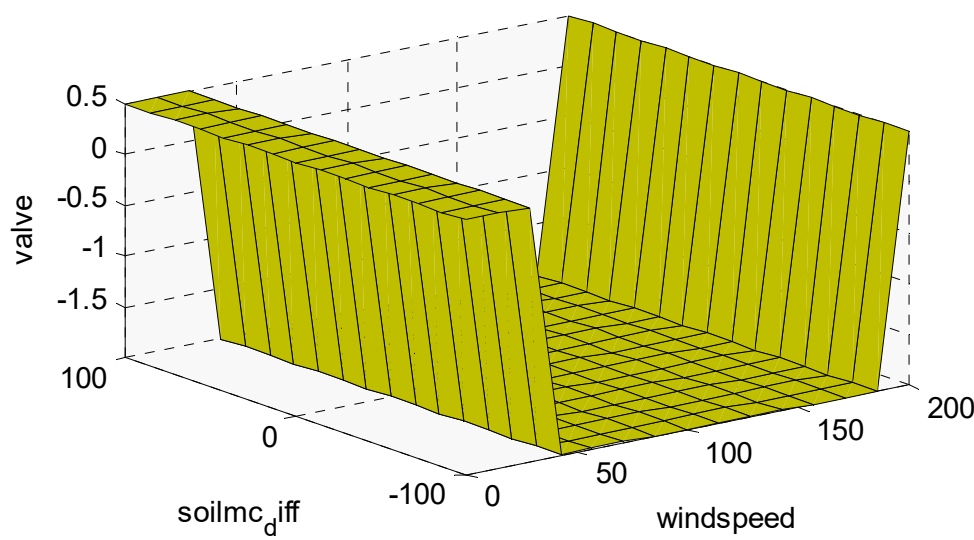

(g)

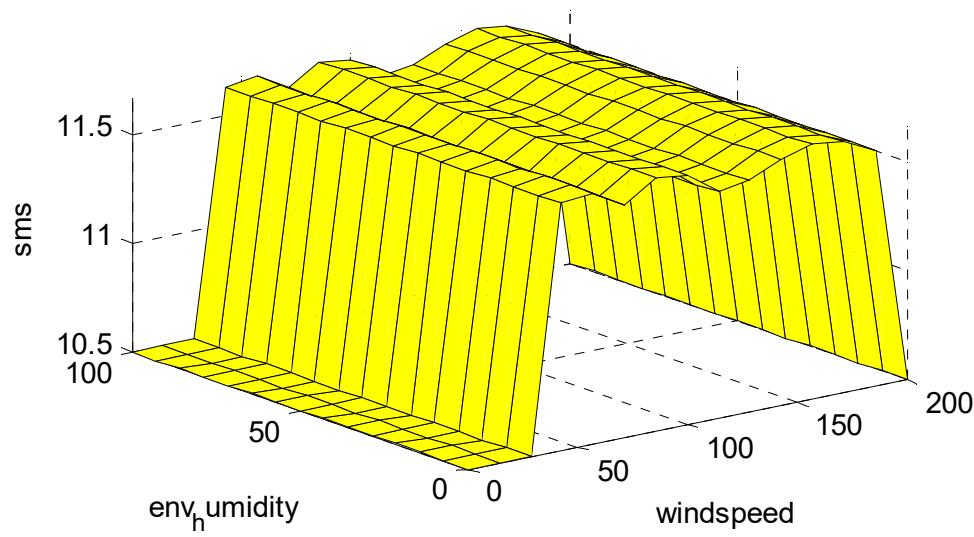

(h)

The crop water need ET crop is calculated on a monthly basis, using the formula:

$$
E T_{\text {crop }}=E T_{0} x K_{c}
$$

where $K_{c}$ is the crop factor for various stages of the plant like initial stage, crop development stage, mid season stage and late season stage.

Error in soil MC $=$ Target Soil MC - Predicted Soil MC

The soil MC prediction is performed using feedforward neural network model by considering sensor input dataset. The error in predicted soil $\mathrm{MC}$ is also calculated and it is listed in Table 3. The predicted soil MC is used to find the soil MC difference which is 
taken input to the fuzzy logic model for irrigation valve position control and generation of notifications. The membership functions of input/output variables of the fuzzy model are shown in Figures 7(a), 7(b), 7(c), 7(d), 7(e) and 7(f). The surface plot of fuzzy logic model with respect to different inputs is shown in Figures $7(\mathrm{~g})$ and $7(\mathrm{~h})$. The fuzzy logic rules are listed in Table 2. All the parameters for fuzzy model are listed in Table 1.

Table 1 Different membership functions for input and output variables

\begin{tabular}{|c|c|c|c|c|c|}
\hline $\begin{array}{l}\text { Soil MC } \\
\text { difference }\end{array}$ & $\begin{array}{l}\text { Membership } \\
\text { index }\end{array}$ & Description & $\begin{array}{l}\text { Environment } \\
\text { temperature }\end{array}$ & $\begin{array}{l}\text { Membership } \\
\text { index }\end{array}$ & Description \\
\hline NL & 1 & Negative large & $\mathrm{L}$ & 1 & $\begin{array}{l}\text { Low condition } \\
(<35)\end{array}$ \\
\hline NR & 2 & Normal & $\mathrm{H}$ & 2 & $\begin{array}{l}\text { High condition } \\
(>35)\end{array}$ \\
\hline PL & 3 & Positive large & & & \\
\hline $\begin{array}{l}\text { Environment } \\
\text { humidity }\end{array}$ & $\begin{array}{l}\text { Membership } \\
\text { index }\end{array}$ & Description & Wind speed & $\begin{array}{l}\text { Membership } \\
\text { index }\end{array}$ & Description \\
\hline $\mathrm{L}$ & 1 & Low humidity & LP & 1 & Low pressure \\
\hline \multirow[t]{6}{*}{$\mathrm{H}$} & 2 & High humidity & DP & 2 & Depression \\
\hline & & & DD & 3 & Deep depression \\
\hline & & & $\mathrm{CS}$ & 4 & Cyclonic storm \\
\hline & & & $\mathrm{SC}$ & 5 & $\begin{array}{l}\text { Severe cyclonic } \\
\text { storm }\end{array}$ \\
\hline & & & VS & 6 & $\begin{array}{l}\text { Very severe } \\
\text { cyclonic storm }\end{array}$ \\
\hline & & & SCS & 7 & $\begin{array}{l}\text { Super cyclonic } \\
\text { storm }\end{array}$ \\
\hline
\end{tabular}

\begin{tabular}{|c|c|c|c|c|c|}
\hline $\begin{array}{l}\text { Sunlight } \\
\text { intensity }\end{array}$ & $\begin{array}{l}\text { Membership } \\
\text { index }\end{array}$ & Description & $\begin{array}{l}\text { Valve } \\
\text { position }\end{array}$ & $\begin{array}{l}\text { Membership } \\
\text { index }\end{array}$ & Description \\
\hline $\mathrm{BR}$ & 1 & Brightest & $\mathrm{CL}$ & 1 & Close \\
\hline BS & 2 & Bright sunlight & MR & 2 & Medium regulated \\
\hline SR & 3 & $\begin{array}{l}\text { Sunrise and } \\
\text { sunset clean sky }\end{array}$ & HR & 3 & High regulated \\
\hline SI & 4 & $\begin{array}{l}\text { Shade } \\
\text { illuminated by } \\
\text { clear sky, } \\
\text { midday }\end{array}$ & & & \\
\hline TP & 5 & $\begin{array}{l}\text { Typical overcast } \\
\text { day }\end{array}$ & & & \\
\hline EX & 6 & $\begin{array}{l}\text { Extreme dark, } \\
\text { storm, cloud, } \\
\text { midday }\end{array}$ & & & \\
\hline
\end{tabular}


Table 1 Different membership functions for input and output variables (continued)

\begin{tabular}{lll}
\hline SMS type & Membership index & Description \\
\hline L & 1 & $\begin{array}{l}\text { Required water level is less and irrigation is required. } \\
\text { Required water level is maintained and irrigation is not } \\
\text { required } \\
\text { Required water level is high and water extraction pump } \\
\text { should be activated } \\
\text { Cyclonic Storm. Irrigation Valve Closed }\end{array}$ \\
H & 2 & Deep Depression. Irrigation Valve Closed \\
ST & 4 & Low Pressure. Irrigation Valve Closed \\
DP & 5 & 6 \\
LP & 6 &
\end{tabular}

Table 2 Some of the symbolic representation of the rules of fuzzy inference system (FIS) for the generation of suitable SMS notifications and control of valve positions

1 (soilmc diff==PL) \& (env temp==H) \& (env humidity==L) \& (windspeed==LP) \& $($ sunlight $==\mathrm{BR})=>($ valve $=\mathrm{HR})(\mathrm{sms}=\mathrm{L})(1)$

2 (soilmc_diff $==\mathrm{PL}) \&($ env_temp $==\mathrm{H}) \&($ env_humidity $==\mathrm{L}) \&($ windspeed $==\mathrm{DP}) \&$ $($ sunlight $==\mathrm{BR})=>($ valve $=\mathrm{HR})(\mathrm{sms}=\mathrm{L})(1)$

3 ( $($ sunlight $==\mathrm{BR})=>($ valve $=-\mathrm{HR})(\mathrm{sms}=\mathrm{L})(1)$

4 (soilmc_diff $==\mathrm{PL}) \&($ env_temp $==\mathrm{H}) \&($ env_humidity $==\mathrm{L}) \&($ windspeed $==\mathrm{LP}) \&$ $($ sunlight $==\mathrm{BS})=>($ valve $=\overline{H R})(\mathrm{sms}=\mathrm{L})(1)$

5 (soilmc_diff $==\mathrm{NL}) \&($ env_temp $==\mathrm{L}) \&($ env_humidity $==\mathrm{H}) \&($ windspeed $==\mathrm{DD}) \&$ $($ sunlight $==\mathrm{SR})=>($ valve $=\overline{\mathrm{CL}})(\mathrm{sms}=\mathrm{H})(1)$

6 (soilmc diff $==\mathrm{NR}) \&($ env temp $==\mathrm{L}) \&($ env humidity $==\mathrm{H}) \&($ windspeed $==\mathrm{LP}) \&$ $($ sunlight $==\mathrm{SI})=>($ valve $=\overline{\mathrm{MR}})(\mathrm{sms}=\mathrm{N})(1)$

7 (soilmc diff $==\mathrm{NR}) \&($ env temp $==\mathrm{L}) \&($ env humidity $==\mathrm{H}) \&$ (windspeed $==\mathrm{DP}) \&$ $($ sunlight $==\mathrm{SI})=>($ valve $=\overline{\mathrm{MR}})(\mathrm{sms}=\mathrm{N})(1)$

8 (soilmc_diff $==\mathrm{NR}) \&($ env_temp $==\mathrm{L}) \&($ env_humidity $==\mathrm{H}) \&($ windspeed $==\mathrm{DD}) \&$ $($ sunlight $==\mathrm{SI})=>($ valve $=\overline{\mathrm{M}} \mathrm{R})(\mathrm{sms}=\mathrm{N})(1)$

9 (env temp $==\mathrm{L}) \&($ env humidity $==\mathrm{H}) \&($ windspeed $==\mathrm{LP}) \&($ sunlight $==\mathrm{TP})=>$ $($ valve $=\mathrm{CL})(\mathrm{sms}=\mathrm{LP})(\overline{1})$

10 (env temp $==\mathrm{L}) \&($ env humidity $==\mathrm{H}) \&($ windspeed $==\mathrm{LP}) \&($ sunlight $==\mathrm{EX})=>$ $($ valve $=\mathrm{CL})(\mathrm{sms}=\mathrm{LP})(\overline{1})$

11 (env_temp $==\mathrm{L}) \&($ env_humidity $==\mathrm{H}) \&($ windspeed $==\mathrm{LP}) \&($ sunlight $==\mathrm{SR})=>$ $($ valve $=\mathrm{CL})(\mathrm{sms}=\mathrm{LP})(\overline{1})$

12 (windspeed $==\mathrm{CS}) \mid($ sunlight $==\mathrm{EX})=>($ valve $=\mathrm{CL})(\mathrm{sms}=\mathrm{ST})(1)$

13 (windspeed $==\mathrm{SC}) \mid($ sunlight $==\mathrm{EX})=>($ valve $=\mathrm{CL})(\mathrm{sms}=\mathrm{ST})(1)$

$14($ windspeed $==\mathrm{VS}) \mid($ sunlight $==\mathrm{EX})=>($ valve $=\mathrm{CL})(\mathrm{sms}=\mathrm{ST})(1)$

15 (windspeed $==\mathrm{SCS}) \mid($ sunlight $==\mathrm{EX})=>($ valve $=\mathrm{CL})(\mathrm{sms}=\mathrm{ST})(1)$

16 (env_humidity $==\mathrm{H}) \&($ windspeed $==\mathrm{CS}) \&($ sunlight $==\mathrm{EX})=>($ valve $=\mathrm{CL})(\mathrm{sms}=\mathrm{ST})(1)$

17 (env_humidity $==\mathrm{H}) \&($ windspeed $==\mathrm{SC}) \&($ sunlight $==\mathrm{EX})=>($ valve $=\mathrm{CL})(\mathrm{sms}=\mathrm{ST})(1)$

18 (env_humidity $==\mathrm{H}) \&($ windspeed $==\mathrm{VS}) \&($ sunlight $==\mathrm{EX})=>($ valve $=\mathrm{CL})(\mathrm{sms}=\mathrm{ST})(1)$

Notes: Fuzzy inference system (FIS) input sequence: [Soil MC difference, Environment Temperature, Environment Humidity, Wind Speed, Sunlight Intensity] FIS output Sequence : [Valve Position, SMS Index] 
The fuzzy system generates suitable SMS index number which is compared in the DSS model to send particular SMS to the farmer's mobile phone handset number. Finally the feedforward neural network and linear regression-based soil MC prediction model and fuzzy logic-based SMS notification model are integrated using LabVIEW interface to process real-time data from the farm land, green house or poly-house (Mohapatra and Lenka, 2015, 2016). The LabVIEW front panel is shown in Figure 8. The LabVIEW system shows all the soil and environmental data along with the SMS type for the particular crop type. Twenty one numbers of different crop types and 11 different soil types are integrated in the system. This system can be analysed by considering wide varieties of crops with all the 11 types of different soil types. To complete this DSS model all data were collected from standard data sources.

Figure 8 Real-time DSS model for smart irrigation using National Instruments LabVIEW (see online version for colours)

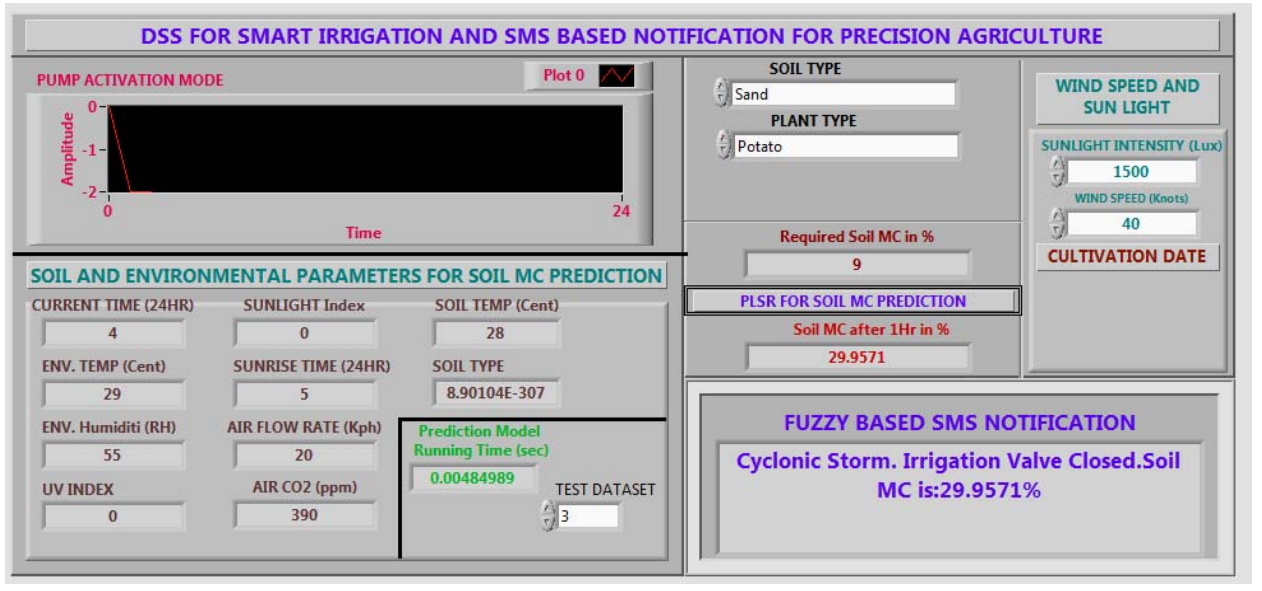

Table 3 Comparative analysis of feedforward neural network model for soil MC prediction

\begin{tabular}{ll}
\hline Parameters & Errors in feedforward neural network model \\
\hline RMSE & 0.428011 \\
RSE & 0.985093 \\
MSE & 0.183193 \\
RPD & 8.251203 \\
Running time (seconds) & 0.022987 \\
\hline
\end{tabular}

A comparative analysis is done on feedforward neural network model for soil MC data prediction along with the algorithm response time required for necessary decision making. The result analysis is done in Table 3. The graphical user interface model for DSS shown in Figure 8 is also integrated with a GSM modem for SMS sending. The interfacing is done using suitable AT command sequences. Some of the AT command sequences are shown in Table 4. The DSS model is tested by taking various sequences of inputs as mentioned in Table 5 and the corresponding irrigation valve position, suitable notifications are also verified. For safety purpose, during cyclonic storm, deep depression and low pressure stage the irrigation system is maintained closed using fuzzy logic 
model. The DSS system is also tested during low water level and low pressure conditions. The farmer's handset SMS notification snapshots are shown in Figure 9 and Figure 10 for two different agriculture conditions.

Table 4 AT command sequence for SMS sending through GSM modem

\begin{tabular}{lcc}
\hline $\begin{array}{l}\text { AT command } \\
\text { sequence }\end{array}$ & AT command & $\begin{array}{c}\text { Modem response for } \\
\text { AT commands }\end{array}$ \\
\hline $1^{\text {st }}$ & $\mathrm{AT}<\mathrm{CR}>$ & $\mathrm{OK}$ \\
$2^{\text {nd }}$ & $\mathrm{AT}+\mathrm{CMGF}=1<\mathrm{CR}>$ & $\mathrm{OK}$ \\
$3^{\text {rd }}$ & $\mathrm{AT}+\mathrm{CMGS}=<$ Farmer's Handset Number $>$ & $+\mathrm{CMGS}:<\mathrm{mr}>$ \\
& $<\mathrm{CR}>$ & $\mathrm{OK}$ \\
& $<$ SMS Notification regarding irrigation status $>$ & \\
& $<$ CTRL-Z $>$ & \\
\hline
\end{tabular}

Notes: N.B. $<$ CR $>=$ ASCII character $13,<$ CTRL-Z $>=$ ASCII character 26 , $<\mathrm{mr}>=$ Message Reference.

Table 5 Test inputs to DSS model and corresponding response from the system

\begin{tabular}{|c|c|c|c|}
\hline $\begin{array}{l}\text { Input parameters [Soil MC } \\
\text { difference (\%), environment } \\
\text { temperature (centigrade), } \\
\text { environment humidity (RH), } \\
\text { wind speed (Knots), sunlight } \\
\text { intensity (Lux)] }\end{array}$ & $\begin{array}{l}\text { Valve } \\
\text { position }\end{array}$ & $\begin{array}{l}\text { Valve } \\
\text { condition }\end{array}$ & SMS type \\
\hline$[7.5872,27,40,40,1500]$ & -1.9995 & Close & $\begin{array}{l}\text { Cyclonic storm. Irrigation valve } \\
\text { closed. }\end{array}$ \\
\hline$[5,40,30,10,110400]$ & 3.9650 & Open & $\begin{array}{l}\text { Required water level is less and } \\
\text { irrigation is required. }\end{array}$ \\
\hline$[-2$ 2938201800] & 1.4990 & $\begin{array}{l}\text { Threshold } \\
\text { level for close }\end{array}$ & $\begin{array}{l}\text { Required water level is maintained } \\
\text { and irrigation is not required. }\end{array}$ \\
\hline$[-52938202300]$ & -1.9930 & Close & $\begin{array}{l}\text { Required water level is high and } \\
\text { water extraction pump should be } \\
\text { activated. }\end{array}$ \\
\hline$\left[\begin{array}{llll}-529 & 38 & 301800\end{array}\right]$ & -1.9995 & Close & $\begin{array}{l}\text { Deep depression. Irrigation Valve } \\
\text { Closed. }\end{array}$ \\
\hline$\left[\begin{array}{llll}-525 & 40 & 10 & 1800\end{array}\right]$ & -1.9986 & Close & $\begin{array}{l}\text { Low pressure. Irrigation Valve } \\
\text { Closed. }\end{array}$ \\
\hline
\end{tabular}

Figure 9 Snapshots of test SMS received in a farmer's handset during low water level in the farm land (see online version for colours)

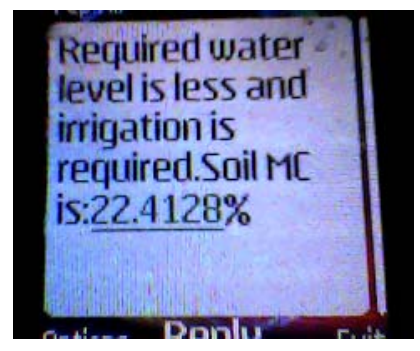


Figure 10 Snapshots of test SMS received in a farmer's handset during low pressure (see online version for colours)

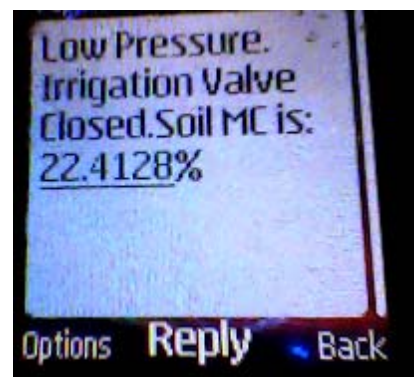

\section{Conclusions}

The system was analysed on the real-time sensor data obtained from a farm land located in Bhubaneswar. Distinct 24 datasets are utilised for soil MC prediction making use of partial least square regression model-based data prediction algorithm. A comparative analysis on feed forward neural network is done for soil MC data prediction along with the algorithm response time. It is observed that the proposed neuro-fuzzy-based hybrid Smart DSS and farmers SMS notification in PA are working efficiently with RSE: 0.985093, RMSE: 0.428011 . This system is analysed with 21 numbers of different crop types as well as 11 different soil types. Distinct SMS notifications are also generated as well as checked emerging fuzzy-based model for the farmer's handset notification. Date wise crop evapotranspiration is also recommended as SMS notifications employing Blaney-Criddle method. It is verified that the SMS notifications are successfully generated and delivered to the actual farmer's handset number.

\section{References}

Aggelopoulou, K., Wulfsohn, D., Fountas, S., Gemtos, T.A., Nanos, G.D. and Blackmore, S. (2010) 'Spatial variability of yield and quality in a small apple orchard', Precision Agriculture, Vol. 11, No. 5, pp.538-556.

Aggelopoulou, K.D., Pateras, D., Fountas, S., Gemtos, T.A. and Nanos, G.D. (2011) 'Soil spatial variability and site-specific fertilization maps in an apple orchard', Precision Agriculture, Vol. 12, No. 1, pp.118-129.

Crow, W.T. and Wood, E.F. (2003) 'The assimilation of remotely sensed soil brightness temperature imagery into a land surface model using ensemble Kalman filtering: a case study based on ESTAR measurements during SGP97', Advances in Water Resources, Vol. 26, No. 2, pp.137-149.

Effendi, Z., Ramli, R. and Ghani, J.A. (2010) 'A back propagation neural networks for grading Jatrophacurcas fruits maturity', American Journal of Applied Sciences, Vol. 7, No. 3, pp.390-394.

Fortin, J.G., Anctil, F., Parent, L.É. and Bolinder, M.A. (2010) 'A neural network experiment on the site-specific simulation of potato tuber growth in Eastern Canada', Computers and Electronics in Agriculture, Vol. 73, No. 2, pp.126-132.

Fountas, S., Aggelopoulou, K., Bouloulis, C., Nanos, G.D., Wulfsohn, D. and Gemtos, T.A. (2011) 'Site-specific management in an olive tree plantation', Precision Agriculture, Vol. 12, No. 2, pp.179-195. 
Fountas, S., Blackmore, S., Gemtos, T.A. and Markinos, T. (2004) 'Trend yield maps in Greece and the UK', Proc. of the 2nd HAICTA Conference, 18-20 March, Vol. 2, pp.65-74, Thessaloniki, Greece.

Gutiérrez, P.A., López-Granados, F., Peña-Barragán, J.M., Jurado-Expósito, M. and HervásMartínez, C. (2008) 'Logistic regression product-unit neural networks for mapping Ridolfia Segetum infestations in sunflower crop using multitemporal remote sensed data', Computers and Electronics in Agriculture, Vol. 64, No. 2, pp.293-306.

Holzman, M.E., Rivas, R. and Piccolo, M.C. (2014) 'Estimating soil moisture and the relationship with crop yield using surface temperature and vegetation index', International Journal of Applied Earth Observation and Geoinformation, May, Vol. 28, pp.181-192, Elsevier.

Miernecki, M., Wigneron, J-P., Lopez-Baeza, E., Kerr, Y., De Jeu, R., De Lannoy, G.J.M., Jackson, T.J., O’Neill, P.E., Schwank, M., Moran, R.F., Bircher, S., Lawrence, H., Mialon, A., Al Bitar, A. and Richaume, P. (2014) 'Comparison of SMOS and SMAP soil moisture retrieval approaches using tower-based radiometer data over a vineyard field', Remote Sensing of Environment, November, Vol. 154, pp.89-101, Elsevier.

Mohapatra, A.G. and Lenka, S.K. (2015) 'Hybrid decision model for weather dependent farm irrigation using resilient backpropagation based neural network pattern classification and fuzzy logic', Proceedings of the Springer Smart Innovation, Systems and Technologies (SIST) Book series, 28-29 November.

Mohapatra, A.G. and Lenka, S.K. (2016) 'Hybrid decision support system using PLSR-fuzzy logic for GSM based site specific irrigation notification and control in precision agriculture', International Journal of Intelligent Systems Technologies and Applications, Vol. 15, No. 1, pp.4-18, Inderscience.

Nocita, M., Stevens, A., Noon, C. and Van Wesemael, B. (2013) 'Prediction of soil organic carbon for different levels of soil moisture using Vis-NIR spectroscopy', Proximal Soil Sensing Papers from the Second Global Workshop on Proximal Soil Sensing, Second Global Workshop on Proximal Soil Sensing, May, Vol. 199, pp.37-42, Geoderma, Elsevier.

Papageorgiou, E.I., Markinos, A. and Gemtos, T.A. (2011) 'Soft computing technique of fuzzy cognitive maps to connect yield defining parameters with yield in cotton crop production in central Greece as a basis for a decision support system for precision agriculture application', in Glykas, M. (Ed.): Fuzzy Cognitive Maps: Advances in Theory, Methodologies, Tools, Applications, Springer Verlag, Berlin.

Yin, Z., Lei, T., Yan, Q., Chen, Z. and Dong, Y. (2013) 'A near-infrared reflectance sensor for soil surface moisture measurement', Computers and Electronics in Agriculture, November, Vol. 99, pp.101-107, Elsevier. 